\title{
Autogestão em construção: uma cooperativa de construção civil do Rio de Janeiro
}

\author{
Elaine Araújo Busnardo ${ }^{1}$ \\ União Capixaba de Ensino Superior (Faesa)
}

\begin{abstract}
Buscou-se compreender mudanças nas condições de vida e trabalho possibilitadas a trabalhadores de uma cooperativa de construção civil. Identificou-se, além da busca pela viabilidade econômica frente às limitações do mercado, o significado que essa forma de trabalho adquire. Analisamos os processos de subjetivação representados pelos indivíduos sobre sua realidade ocupacional, a organização do trabalho, as práticas cooperativas, a distribuição dos rendimentos financeiros, além de aspectos relacionados à saúde e à participação social. Apesar das dificuldades em ultrapassar uma cultura do assalariamento, submissão e naturalização dos riscos ocupacionais, foram constatadas mudanças sociais significativas e novas formas de se promover e produzir saúde, do ponto de vista psicossocial. Os resultados mostram que a experiência, além de constituir um meio viável de sobrevivência e de melhoria da qualidade de vida, possibilita o aperfeiçoamento profissional e o exercício da autonomia, da cooperação, da solidariedade e um envolvimento crescente com as questões sociais, políticas e comunitárias.
\end{abstract}

Palavras chave: Economia solidária, Saúde do trabalhador, Cooperativismo, Economia social.

Development of self-management: a cooperative of civil building in Rio de Janeiro

In this assignment, we tried to understand the changes on life and work conditions that was possible thanks to a enterprise based on the ideals spread by economy of solidarity. We identified, beyond the route ran to guarantee the economic viability, that work becomes with a new mean based on another views of being, of thinking, of doing, of living on/about work. We analyzed the social representations of those workers about their occupational reality, work organization, cooperative practices and the distribution of financial incomes - also about health and social participation. It was detected that, in spite of the difficulties on overcome all the submissive culture and the usual way of understand occupational risks as normal, this alternative has made possible significant social changes and another ways of promote and produce health, particularly on psychosocial point of view. The obtained results shows that this experience beyond constitute a feasible way of surviving and a way of improving life quality, makes possible the professional improvement and the exercise of autonomy, freedom with responsibility, cooperation and solidarity. It was too noticed that there was a growing involvement with socials, political and communities issues.

Keywords: Economy of solidarity, Worker's health, Cooperative movement, Social economics.

\section{Introdução}

\begin{abstract}
A s estatísticas do $\mathrm{IBGE}^{2}$ mostram que, nos anos 90 e início da década posterior, houve queda crescente do emprego e um aumento da sub-contratação de trabalhadores temporários. Cada vez mais, grande número de empresas tende a reduzir sua força de trabalho ou a precarizar suas formas de contratação. Ao mesmo tempo, forma-se um núcleo mais estável de mão-de-obra com exigências de maior qualificação, flexibilidade e polivalência, surgindo um número crescente de trabalhos precarizados. Muitas empresas vêm adotando, inclusive, formas de trabalho informal e mal pago, ressaltando-se o trabalho em domicílio, muitas vezes realizado por mulheres, com ajuda de crianças.
\end{abstract}

\footnotetext{
1 Psicóloga pela Universidade Federal do Espírito Santo. Especialista em Psicologia Jurídica pela Universidade Estadual do Rio de Janeiro. Mestre em Saúde Pública (subárea Saúde, Trabalho e Ambiente) pela Escola Nacional de Saúde Pública da Fundação Oswaldo Cruz. Professora do curso de Administração do Campus III da União Capixaba de Ensino Superior (Faesa).
}

2 IBGE. Instituto Brasileiro de Geografia e Estatística. www.ibge.org.br. Acesso em janeiro de 2004. 
Aliada a todos esses fatores, coloca-se uma crise das políticas sociais, na qual o Estado, em sua dificuldade para atuar na intermediação dos mercados, também não consegue dar conta das conseqüências dos processos de empobrecimento e desemprego estrutural, limitando-se a ações pontuais, assistencialistas e paliativas que não são suficientes para atender à grande parte dos indivíduos que delas necessitam.

Concordamos com Lisboa (1999) ao afirmar que hoje vivemos em uma sociedade de trabalhadores sem trabalho. Diz-se isso porque somos construídos em torno da ética do trabalho, porque o temos como princípio fundamental e organizador da vida - vivemos para trabalhar. É pelo exercício de uma profissão que as pessoas adquirem identidade social. Entretanto, esse mercado se encolhe como resultado tanto do surgimento de novos padrões de organização produtiva (terceirização, flexibilização, com a conseqüente precarização das relações de trabalho), quanto do advento de novas tecnologias e conseqüente redução na quantidade do trabalho socialmente necessário (Lisboa, 1999).

Em geral, esse contexto tem levado ao desenvolvimento de formas alternativas de geração de emprego e renda: algumas individuais, outras coletivas, muitas sendo empurradas para a informalidade ou para a ilegalidade; outras assumindo formas de organização que divergem da lógica exploratória e autoritária, ainda predominante no mundo do trabalho. Uma dessas formas coletivas é conhecida como economia solidária.

O termo economia solidária designa atividades econômicas centradas sobre a necessidade de atender às demandas locais. É uma tentativa de autogerar riquezas para suprir os problemas sociais (França Filho, 2002). A forma mais representativa de economia solidária é o cooperativismo, cuja doutrina é regida por sete princípios básicos: adesão livre e voluntária; controle democrático; participação econômica dos sócios; autonomia e independência; educação, treinamento e informação; cooperação entre cooperativas; preocupação com a comunidade.

De todos esses princípios, a característica que fica mais marcante no cooperativismo é a idéia de autogestão que, segundo Albuquerque (2003), pode ser definida como o conjunto de práticas sociais que se caracteriza pela natureza democrática da tomada de decisões que propiciam a autonomia de um coletivo. Isso significa dizer que uma empresa autogerida é uma organização produtiva na qual o poder de decisão, formalmente, pertence igualmente a todo o coletivo de trabalhadores. Também o ganho líquido é dividido entre os trabalhadores segundo regras estatutárias ou acordadas em assembléias gerais.

Neste artigo, apresentamos uma pesquisa realizada junto à cooperativa Constrói Fácil, empreendimento escolhido em função de sua trajetória e participação junto a movimentos e mobilizações locais e regionais em favor da economia solidária. Trata-se de uma cooperativa de prestação de serviços em construção civil localizada na zona oeste da cidade do Rio de Janeiro. Sua forma de trabalho consiste em parcerias junto a investidores externos para a construção de casas ou outros tipos de instalações prediais. Em seus acordos, cabe ao investidor a aplicação de capital para a compra do terreno e do material de construção e para remuneração da mão-de-obra; à cooperativa cabe a elaboração do projeto de construção, o fornecimento de mão de obra e a execução do trabalho. Ao final da obra, os lucros decorrentes da venda do imóvel são de direito do investidor, cabendo a ele prover o saldo combinado para a remuneração dos trabalhadores.

A construção civil é, sem dúvida, uma categoria caracterizada por um processo de trabalho altamente desgastante, em geral formado por mão-de-obra abundante, mal paga e com baixo grau de instrução. Nos canteiros de obra, é comum a ocorrência de acidentes, inclusive fatais. Pesa sobre esses trabalhadores o constante medo do desemprego, já que a grande maioria é constituída por mão-de-obra terceirizada. Muitos deles não possuem contrato formal, ficando sem proteção social, submetidos a condições deploráveis de trabalho, em total desrespeito às cláusulas elementares da convenção coletiva da categoria. Dentro 
dessas condições de precariedade, destacam-se a irresponsabilidade e a omissão das empreiteiras, a alta rotatividade, o uso de alojamentos precários e improvisados, condições insalubres de alimentação e de trabalho e horários excessivamente estendidos, sem um acompanhamento salarial compatível.

Em função de todas essas variáveis, julgamos ser essa cooperativa, a Constrói Fácil, um campo fértil para a produção de estudos sobre economia solidária e saúde do trabalhador, já que a relação entre construção civil e economia solidária é carregada de desafios. Se o setor de construção civil caracteriza-se por todas as precariedades acima citadas, o referencial da economia solidária prega exatamente o seu oposto: pressupõe-se que os trabalhadores tenham controle sobre o seu próprio processo de trabalho, influenciando nas decisões a ele relativas; também não há o medo constante de ser demitido, já que esses trabalhadores são donos do seu próprio negócio; em relação aos direitos trabalhistas, a lei estabelece que esses indivíduos devem se registrar e pagar INSS como autônomos, fazendo jus a algumas garantias previdenciárias. Por outro lado, há um aumento das responsabilidades, já que caberá a todos a responsabilidade tanto pela execução, quanto pelo planejamento e pelas decisões referentes à cooperativa.

\section{Percorrendo uma cooperativa de construção civil: a condução do processo investigativo}

Inseridos no cotidiano da cooperativa Constrói Fácil, buscamos investigar o que havia de novidade: o que uma experiência de economia solidária podia trazer de diferente para a organização do trabalho e como esse diferencial poderia possibilitar e promover a saúde desses trabalhadores em questão, do ponto de vista psicossocial. Ao falar em transformações da organização do trabalho, falamos de um redimensionamento das formas de estar no trabalho e também da possibilidade de agregar outras habilidades e de outras formas de ser, pensar, dialogar e comportar-se no trabalho e nas outras esferas da vida social. Acreditamos que essas transformações podem transcender a esfera individual e instituir novas relações com o coletivo, que se expressam através de uma mudança de atitudes junto à família e aos diversos processos decisórios e criativos do trabalho, da comunidade e da vida política em geral.

Nesse sentido, a nossa hipótese era a de que os referenciais da economia solidária poderiam apontar para uma desejada emancipação social dos sujeitos cooperados. Por emancipação social designamos o processo ideológico e histórico de liberação de comunidades políticas ou de grupos sociais, da dependência, da tutela e da dominação nas esferas econômicas, sociais e culturais. Emancipar-se significa livrar-se do poder exercido por outros, conquistando, ao mesmo tempo, a plena capacidade civil e de cidadania no Estado democrático de direito.

Em nosso percurso, trabalhamos com os conceitos de produção de subjetividades e singularização, além do conceito de emancipação social, já especificado anteriormente. Quando dizemos produção de subjetividades, estamos querendo apontar para o seu caráter não natural, isto é, para os processos históricos de montagem das formas subjetivas. Nessa perspectiva, a subjetividade não se confunde com algo transcendente, algo já-dado. Referimo-nos à maneira pela qual, a cada momento da história, prevalecem certas relações de poder-saber que produzem objetos, sujeitos, necessidades e desejos (Barros, 1999).

Em nossa pesquisa, estivemos constantemente nos remetendo às diferentes possibilidades de organização do trabalho que podem ser efetivadas através da economia solidária. Assim, entendemos que o mundo atual institui uma forma de ser sujeito que 
captura modos de existir, tornando-os quase homogêneos. Contudo, nossos corpos, quase que invisivelmente, estão sempre instituindo modalidades de singularização à revelia dessa homogeneidade. Nesse sentido, a singularização constitui-se como um movimento que, através do desejo, não nos deixa em paz; são movimentos de protesto do inconsciente contra esse processo de homogeneização. Trata-se da afirmação de novas possibilidades de existência.

Competição, isolamento, solidão, exploração e passividade dos indivíduos são características disseminadas pelo capitalismo ocidental. Tais características influenciam os indivíduos, mas não determinam uma "natureza" ou "essência" que assim o configure. Tais características são produzidas historicamente dessa forma. Isto é, houve uma série de situações que convergiram para a construção desse modo de ser indivíduo, desse modo de subjetivação. Porém, se esse indivíduo é produzido historicamente e não a priori, é possível que ele se diferencie e, de fato, impomos resistências a esse modo dominante. E são essas resistências que caracterizam os movimentos de singularização.

Partimos da hipótese inicial de que a economia solidária abre caminho para um possível processo de singularização dos indivíduos através da conformação de novos processos de subjetivação. Através dela afirmam-se outros valores e, conseqüentemente, outros sujeitos. Acreditamos que há algo que se passa nesse meio de convivência que permite o despertar de novas idéias e de novos discursos. Essa dinâmica é o que chamamos de processos de subjetivação.

Para este trabalho, os interesses foram guiados no intuito de entender como funciona o processo de trabalho em empreendimentos de economia solidária, o que é diferente, o que é novidade e, principalmente, o que pode ser encarado como uma ruptura capaz de instituir resistências à conformação de indivíduos generalizados e de promover a emancipação social desses trabalhadores, produzindo saúde em seus aspectos mais amplos.

Este estudo partiu da perspectiva do campo da saúde do trabalhador, cujo objeto de estudo é o processo saúde-doença dos grupos humanos, tendo o trabalho como organizador da vida social, espaço de dominação e submissão dos trabalhadores pelo capital, mas, igualmente, espaço de resistência, de constituição e do fazer histórico. A saúde do trabalhador busca a explicação sobre a relação saúde-doença nos trabalhadores, por meio do estudo dos processos de trabalho, de forma articulada com o conjunto de valores, crenças, idéias, as representações sociais e a possibilidade do consumo de bens e de serviços na moderna civilização urbano-industrial (Mendes \& Dias, 1991).

Partindo do histórico narrado pelos trabalhadores da cooperativa Constrói Fácil, interessamo-nos por sua origem, pelos passos que vêm sendo dados, pelas dificuldades enfrentadas, pelos obstáculos ultrapassados, por suas expectativas futuras e pela forma como têm se constituído enquanto um empreendimento autogestionário. Entendendo ser esse um difícil processo de construção e que existem barreiras ligadas a uma cultura de assalariamento e submissão, utilizamos o discurso desses sujeitos - que é uma amostra de como percebem essa experiência que vivenciam - para chegar ao foco dos nossos questionamentos. Nesse percurso, temos plena ciência de que esses indivíduos são diferentes e que elaboram percepções distintas, que variam conforme suas histórias de vida, os contatos que tiveram, o tempo que possuem na cooperativa, a forma como encaram as diversas situações etc.

Como instrumento de coleta, utilizamos entrevistas individuais ou coletivas semiestruturadas, marcadas conforme interesse e disponibilidade dos cooperados, e a observação participante do cotidiano do trabalho. Todas as entrevistas foram gravadas e realizadas dentro de seu próprio ambiente de trabalho, tendo sido dificultadas pelo alto nível de ruídos presente nas obras. 


\section{Encontros e desencontros no processo cooperativo: resultados e análise}

Em sua maioria, os entrevistados são pessoas que nunca tiveram qualquer experiência anterior com o cooperativismo, estando ainda num processo de construção desse entendimento e dessa forma de ser trabalhador. A maioria do grupo é formada por pessoas com baixa escolaridade que trabalharam quase que exclusivamente no campo da construção civil. Muitos deles afirmam gostar do que fazem, embora poucos formulem planos de continuar trabalhando em obras por muitos anos.

O grupo Constrói Fácil tem um regimento interno, que foi escrito ao longo de dois anos de discussões e de deliberações até sua efetiva aprovação em assembléia geral. Esse regimento determina os objetivos da cooperativa, suas normas gerais de funcionamento, regras para controle de gastos, entrada e saída de associados, formas de pagamento dos associados, regras de administração, dentre outras normatizações. De acordo com esse documento, todas as funções de planejamento da cooperativa devem ser realizadas por comissões, sendo obrigatória a participação de todos em pelo menos um desses grupos de trabalho. São três os grupos: comissão de obra e segurança, comissão de formação e mobilização e comissão de finanças.

O regimento interno também prevê a composição de um conselho deliberativo, responsável pela tomada de decisões, pelas providências previstas no documento e pela representação dos cooperados junto aos investidores, às outras cooperativas e às demais associações ou movimentos com os quais mantém relações. Em caso de decisões não previstas no regimento, devem ser convocadas assembléias gerais. O conselho deliberativo é eleito em assembléia, podendo qualquer membro associado convocar uma reunião extraordinária para contestar alguma decisão ou propor novas sugestões. O conselho deliberativo exerce sua função sem autoritarismo, incentivando a participação e a responsabilidade. Não há relações hierárquicas no grupo, posto que todos são donos da cooperativa. Há, entretanto, divisão de funções - o que diferencia a atividade e o pagamento semanal dos membros. Tal pagamento é denominado retirada e é calculado de acordo com a função exercida e com o número de horas trabalhadas no período.

As funções desempenhadas são: coordenador, profissional (pedreiro, eletricista, bombeiro etc.), meio-oficial, aprendiz ou ajudante. Em geral, existe a possibilidade de aprendizagem de novos ofícios, com chances de troca de função. Os próprios colegas se ajudam e ensinam uns aos outros, contribuindo para uma maior aprendizagem no trabalho. Também existe a possibilidade de ascensão dentro da cooperativa. Há uma espécie de plano de carreira, que começa com a função de ajudante de pedreiro e pode terminar no papel de coordenador de obra. À medida que se cresce nesse patamar, aumenta o valor das retiradas financeiras. Os colegas ensinam aos outros suas atribuições e, conforme aparecem oportunidades, as pessoas vão assumindo novas funções. $O$ critério para ascensão baseia-se na capacitação e na necessidade do trabalhador. A necessidade é avaliada pelos seguintes fatores: número de integrantes da família, situação domiciliar, caso de doença em família etc.

É interessante notar que, nessa cooperativa, convivem duas formas de organização social: uma antiga, proveniente das corporações de ofício (a especialização e a aprendizagem das funções, a ascensão conforme aprendizagem, o apoio mútuo e a não utilização de máquinas etc.) e outra moderna, advinda da revolução industrial e da revolução francesa (o cooperativismo). A primeira forma de organização, predominante até meados do século XV tinha por objetivo assegurar o "justo preço" por seus produtos e o status social de seus membros. A sustentação desse preço era, entretanto, incompatível com a busca incessante do aumento da produtividade, característica do capitalismo. A fidelidade às tradições, a conservação dos hábitos e costumes, a manutenção da hierarquia social eram valores 
supremos nas corporações de ofícios, aos quais se procurava adaptar a prática. Esse mundo foi rudemente abalado no século XV pela descoberta das vias marítimas da Europa à América e ao Extremo Oriente, que deu enorme impulso ao comércio mundial, abrindo ao capital comercial perspectivas até então inimagináveis de desenvolvimento.

A outra forma de organização que coexiste nessa cooperativa é moderna, advinda da revolução industrial e da revolução francesa: o cooperativismo, no qual se estende o poder de decisão a todos os trabalhadores, aumentando o seu grau de liberdade em relação ao trabalho. A organização semelhante à corporação de ofício organiza o trabalho, a outra organiza a política interna e a gestão.

\section{Valorização do trabalho}

Uma das formas que utilizamos para entender os valores atribuídos ao trabalho na cooperativa foi pedir aos cooperados que comparassem sua situação atual de trabalho com a que teriam se estivessem trabalhando para uma empresa. Apresentamos abaixo as principais constatações por eles declaradas.

O aspecto positivo mais apontado pelos cooperados foi a liberdade, a possibilidade de auto-regular seus horários e de faltar quando necessário. Segundo os entrevistados, essa liberdade não compromete a produtividade e até ajuda a aumentá-la, já que quanto mais se trabalha, maior é a retirada de cada trabalhador.

Não tem dinheiro que pague essa liberdade que a gente tem de trabalhar. Não tem que aturar patrão. Na empresa, se você faz uma coisa errada, você está ferrado. Aqui a gente tem o direito de errar e de consertar o erro (...) Quem já sentiu o gostinho de tomar decisão, de ter liberdade, é difícil acostumar com outra coisa (tesoureiro, membro do conselho deliberativo).

A essa maior liberdade alia-se a um conseqüente aumento das responsabilidades, conforme mostrado na fala abaixo:

Quando contratado por uma empresa você está realmente livre de trabalho no final do expediente; acaba o seu horário e não precisa mais pensar em trabalho. Na cooperativa não: as preocupações são levadas para casa, pois há decisões a serem tomadas todos os dias (tesoureiro, membro do conselho deliberativo).

A ausência da relação de subordinação a uma chefia também foi apontada como fator positivo, mesmo com o aumento da responsabilidade que essa situação impõe. Por outro lado, a falta de controle hierárquico possibilita alguns desperdícios e abusos por parte de determinados colegas que deixam o tempo passar trabalhando pouco e comprometendo a produtividade do grupo.

Aqui o patrão é você mesmo. Aí você experimenta a sua norma (coordenador de obra).

Entre alguns membros mais antigos da cooperativa, apareceu uma associação do trabalho com o termo criatividade, um descobrir-se criativo. Essa criatividade, segundo eles, torna-se especialmente necessária no momento de organizar reuniões de formação e de explicar certos assuntos durante as assembléias e reuniões deliberativas.

O que o cooperativismo significa para a minha vida? (...) Criatividade. Isso porque toda hora eu tenho que buscar uma coisa nova para melhorar, pra explicar melhor para os outros, para 
ajudar a crescer a cooperativa (membro do conselho deliberativo e da comissão de formação).

Dentro desse mesmo grupo de trabalhadores, predominou o discurso da mudança, por exemplo:

O trabalho mudou a minha vida (...) Eu hoje sou uma pessoa melhor (pedreiro).

Outros trabalhadores comparam sua vivência laboral com o emprego numa empresa privada e mencionam a restrição de direitos e o valor das retiradas financeiras. Segundo eles, a retirada financeira pela cooperativa é mais alta do que aquela que teriam acesso caso estivessem vinculados a um emprego formal. Por outro lado, na cooperativa, perdem alguns direitos oferecidos quando se registra uma carteira de trabalho. Esse fato, porém, não é por todos considerado como um fator de perda, já que muitas das empresas da construção, mesmo quando contratam, não assinam a carteira do operário.

Para alguns trabalhadores, as comparações parecem se concentrar em percepções materiais e ligadas à estabilidade ocupacional, com ênfase para o seu potencial de sustento, ganhos financeiros e sobrevivência. Nesse sentido, não vêem grandes diferenças entre estar na cooperativa ou em outro local de trabalho.

Aqui a gente ganha mais do que numa firma. Também aqui não falta trabalho (...) Não ter patrão é bom porque tem mais liberdade. Mas é também ruim porque não tem vale transporte nem refeição. Mas no final do ano é melhor por causa da divisão do dinheiro (meio-oficial).

Alguns trabalhadores apontam como diferencial da cooperativa o contato tido com os colegas em momentos distintos do horário de trabalho, como durante as reuniões e assembléias ou durante os eventos de confraternização eventualmente organizados pelo grupo. Também foi vivamente apontada a ênfase na solidariedade priorizada pela cooperativa, através de suporte a projetos sociais e de contribuições financeiras a um fundo de solidariedade, que serve aos próprios cooperados em caso de necessidade.

Numa empresa, tiram o couro todo dia. Se você fica doente ninguém ajuda e te mandam embora. Aqui a gente paga o dia de quem tá parado. Tem solidariedade (servente).

Em geral, a principal vantagem que eles realçam é que são os donos da cooperativa, sentindo-se responsáveis por ela. É interessante notar que, em nenhum momento, houve reclamações sobre a organização do trabalho - fator indispensável a ser considerado nos estudos sobre satisfação no trabalho e saúde do trabalhador.

Entre alguns cooperados, ao compararem seu trabalho na cooperativa com uma experiência de trabalho assalariado, foi freqüente a associação entre assalariamento e escravidão, perceptível claramente no discurso abaixo:

Você deixa de ser um boneco para ser alguém (...) O pessoal que não toma decisão não é ele mesmo. Acha que tem que imitar o outro para ser alguém (servente).

Em todos os entrevistados foi visível o discurso orgulhoso sobre a qualidade do serviço que prestam, constantemente reconhecida pelos proprietários das obras concluídas. Acreditam em seu potencial (enquanto um grupo de trabalhadores que se esforça por fazer um bom serviço) e na possibilidade de um grande crescimento e de desenvolvimento da cooperativa. É perceptível também uma forte relação de pertencimento e posse. Eles percebem que a cooperativa é uma conquista e que essa conquista é fruto do seu trabalho. 
Você veio pesquisar a gente porque a gente é bom, né? (eletricista).

É um orgulho ter essa cooperativa em pé (coordenador de obra).

Cabe uma ressalva percebida em todas as entrevistas. A grande maioria dos cooperados diz que gosta do trabalho que exerce, mas são poucos aqueles que pretendem continuar no ramo da construção civil por mais alguns anos de sua vida. Foi grande o número de associados que expressou desejo de mudar de área, migrando principalmente para o comércio. Dentre os motivos de desgosto com a construção civil, destaca-se o tipo de trabalho, que é pesado e arriscado, além de pouco valorizado, haja visto os baixos salários pagos a essa categoria pelo mercado formal.

O gari ganha igual ao salário de um coordenador. Obra é um trabalho muito pesado e não é valorizado. Tem trabalho leve que tem melhor salário (coordenador).

Predomina também uma romantização das possibilidades de constituição de um negócio próprio. Sem conhecer as altas estatísticas de quebra e endividamento da grande maioria dos empreendimentos individuais recentes, eles acreditam no enriquecimento rápido se investirem em um empreendimento individual, especialmente um bar, um restaurante ou uma pequena loja de artigos gerais.

Vale frisar que esse sonho de conseguir montar um comércio é contraditório com o próprio discurso do cooperativismo. Por um lado, o trabalhador diz que está tudo bom, que está satisfeito na cooperativa, que aprova a liberdade e a autonomia no trabalho; por outro, ele quer ser dono de um empreendimento onde sujeitará e subordinará outros trabalhadores, onde deverá se guiar por princípios do mercado competitivo capitalista. Porém, mesmo diante dessa contradição, mostram-se algumas dimensões da busca pela emancipação social, do desejo de se autogerir, de não necessitar de qualquer tipo tutela ou dominação nas esferas econômicas, sociais e culturais.

\section{Mudanças}

Muitos acreditam que a experiência do cooperativismo possibilitou mudanças diversas em suas vidas. Alguns relatam que a influência do grupo ajudou a efetivar melhorias no trato individual com a família e com outras pessoas, pois aprenderam a ser mais pacientes, a ouvir o outro e a colocar-se em seu lugar. Isso é explicitado na fala abaixo:

Aprendi a me relacionar melhor com as pessoas. Essa liberdade ajuda. (...) As pessoas acreditam no potencial e ensinam quando a gente pergunta (meio-oficial).

Outros relatam que passaram a demonstrar maior interesse por assuntos coletivos, sociais, políticos e alguns, inclusive, filiaram-se a partidos políticos após um contato maior com a cooperativa.

Acho que a formação e as comissões ampliaram minha mente (pedreiro).

Eu participo. É legal. (...) Gosto das reuniões sobre política. Agora estou me interessando mais.

(...) A gente vai sabendo das coisas... (servente).

Entretanto, a maioria afirma que qualquer mudança só ocorre se houver iniciativa e interesse individual. Criticam alguns colegas por não se interessarem pelos assuntos da cooperativa e por limitarem suas preocupações a questões puramente financeiras. 
Para quem quer, a vida muda. Mas tem gente que não enxerga que é uma cooperativa que é nossa, acham que é uma firma. Quando você leva a sério, muita coisa muda (carpinteiro).

Nas entrevistas, foram ouvidos relatos interessantíssimos de mudanças propiciadas pela atitude paciente e tolerante do grupo, como abandono do alcoolismo e o estabelecimento de melhores relações familiares e profissionais. Também são visíveis as demonstrações positivas de auto-estima desenvolvidas com o auxílio do grupo.

A realidade lá era oitenta por cento de alcoólatras, totalmente sem controle. Tinha pai de criança que era alcoólatra, que batia muito nos filhos e que, quando ganhava comida escondia, para não dividir com eles (Arnóbio, coordenador geral e membro do conselho deliberativo).

A gente aqui começa a ter a idéia de ajudar os outros (...) A gente conhece gente interessante, outras histórias. Isso envolve (...) Fico mais solidário. Isso é bom e importante (pedreiro).

Já fui bebedor. Hoje parei. Acho que o trabalho ajudou (pedreiro).

Arnóbio, fundador da cooperativa, considera que, do ponto de vista financeiro, perdeu muito ao optar pela cooperativa. Isso porque, se tivesse mantido sua sub-empreiteira, estaria ganhando muito mais dinheiro hoje. Entretanto, ele acredita que fez a escolha correta, pois viu transformações fantásticas ocorrerem ao longo desses anos, referindo-se a mudanças de atitudes e modos de vida que, segundo ele, foram possibilitadas pela solidariedade, pela tolerância e pela compreensão do grupo.

Eu diria que na parte financeira foi um fracasso total. Eu tinha uma sub-empreiteira desde 1976 e hoje eu estaria ganhando muito mais. (...) Aí vem a grande riqueza, o grande patrimônio. Apesar de viver numa sociedade egoísta, você conhece pessoas maravilhosas. A gente viu acontecer transformações incríveis nas pessoas. Este é um patrimônio que ninguém tira (...) Tudo o que eu vi acontecer é fantástico. É uma minoria, infelizmente, mas cada história é de uma riqueza imensa (Arnóbio).

Grande parte dos cooperados acredita que a nova experiência proporcionou uma mudança de atitudes e pensamentos através de discussões em grupo e do contato com lideranças fortes. Contam que passaram a assumir uma postura mais crítica e cooperativa diante dos problemas sociais, além de desenvolver maior autonomia e autoconfiança para a tomada de decisões.

Acho que amadureci (...) Mudei totalmente. Aprendi a chegar na hora, a produzir mais... (pedreiro).

Hoje não fico parado em casa. Eu tenho até vergonha de ficar parado. Não gosto de preguiça (coordenador de obra).

Percebe-se que os processos autogestionários da cooperativa possibilitaram também uma atitude menos submissa perante os outros grupos com os quais esses trabalhadores convivem.

Quem já sentiu o gostinho de tomar decisão, de ter liberdade, é difícil acostumar com outra coisa. (...) Eu acho que a cooperativa já tem uma base de mais ou menos doze pessoas que não aceitaria outra coisa, porque valoriza e que acredita nessa proposta (tesoureiro).

Para todos, a presença e a atitude paciente e persistente de seu líder foi fundamental para a constituição de movimentos de solidariedade e de ajuda mútua dentro da cooperativa. Também destacam a confiança do grupo e a disponibilidade para ensinar, possibilitando que um auxiliar de pedreiro possa um dia se tornar um coordenador de obra. Dentre aqueles que 
participam das reuniões de formação, a grande maioria acredita na sua importância ao fazer refletir sobre as idéias de solidariedade e de cooperação, podendo influenciar modificações individuais e coletivas.

A cooperativa me ajudou a pensar assim. Tudo ajuda: as conversas, as ações, as reuniões, o contato com as pessoas, a observação do cotidiano, a afinidade com o pensamento, participar... (servente).

Aprendi aqui que tem que ajudar os outros e cooperar, compartilhar (servente).

Também, diferentemente do que é comum no ramo da construção civil, há preocupação com o aperfeiçoamento profissional e com o oferecimento de oportunidades para a ascensão dentro da estrutura de cargos e funções da cooperativa. Além do incentivo ao ensino passado pelos colegas no dia-a-dia, há reuniões onde se procura aperfeiçoar e adquirir novos conhecimentos.

\title{
Ações solidárias e abertura para a comunidade
}

\author{
Uma andorinha só não faz verão. Todo mundo se uniu \\ para construir a Constrói Fácil (ajudante).
}

Há inúmeros movimentos de solidariedade que ocorrem por iniciativa da Constrói Fácil. A própria origem da cooperativa, está ligada a uma ação de solidariedade, o Projeto Shangri-lá̉. De lá para cá muita coisa mudou na comunidade Shangri-lá. Muitos moradores aderiram à cooperativa e ainda hoje estão lá trabalhando. Outros encontraram emprego em diferentes lugares. Alguns outros continuam parados, sem solução a vista, embora tenham a cooperativa como possibilidade permanente de auxílio às suas necessidades.

Fruto da cooperativa Constrói Fácil é também o projeto Casa $\mathcal{E}$ Cidadania ${ }^{4}$, que surgiu da percepção de uma contradição entre os próprios trabalhadores: "eu construo casa, mas não tenho casa". É interessante observar que a realização desse projeto aponta para um princípio de desalienação do trabalhador, pois ele se inclui como responsável pelo conteúdo e pelo produto final de sua tarefa, passando a interagir de forma criadora, introduzindo mudanças que afetarão não só o seu cotidiano de trabalho, mas as próprias condições de vida além jornada.

Além de Shangri-lá e do Casa \& Cidadania, o grupo contribui financeiramente para projetos sociais, como o Ação da Cidadania, além de participações individuais em grupos comunitários e religiosos. Há também um fundo de solidariedade com o qual contribui a cooperativa. Esse fundo é utilizado em caso de necessidade por parte de algum cooperado (médico, remédios, outras situações de necessidade), devendo ser ressarcido após uso. Adicionalmente, há uma contribuição semanal de cada cooperado que se destina a prover o

\footnotetext{
3 O projeto Shangri-lá foi uma iniciativa de membros da Igreja Católica, que promoveram mutirões para construção de casas para famílias de uma comunidade carente do Rio de Janeiro. Após a construção das casas, a pequena comunidade passou a ser conhecida como Shangri-lá. Ali também foi percebida a necessidade de se gerar renda e subsistência para essas pessoas. Daí surgiu a idéia de uma cooperativa, encabeçada pelo Sr. Arnóbio que, na época, era um pequeno empresário local. Ele acreditou na idéia e trouxe sua experiência de empreendedor para auxiliar na construção da cooperativa Constrói Fácil.

4 O Projeto Casa \& Cidadania foi criado pelos trabalhadores da Constrói Fácil com o objetivo de construir casas para os membros da cooperativa a partir de mutirões com os próprios associados. Esse projeto surgiu ao constatarem a imensa contradição que envolvia suas profissões e suas condições de moradia, pois construíam casas grandes e bonitas, com acabamentos admiráveis e, ao mesmo tempo, muitos pagavam aluguel ou moravam em casas pequenas, feias, mal conservadas e mal construídas, mesmo podendo e sabendo como melhorar suas condições de moradia. Os mutirões são voluntários e acontecem aos sábados, domingos e feriados.
} 
sustento de alguns associados que estão parados em virtude da ausência de obras suficientes para agregar todo o grupo.

A cooperativa ajuda um grupo com alimentos e colabora sempre que alguém necessita. Você sabe, né... os que foram dispensados. Cada um dá dez reais para pagar a semana daqueles que estão parados por falta de obra (ajudante).

Em épocas de eleição, é comum que a cooperativa promova reuniões para decisão de votos. A maioria dos cooperados baseia-se na opinião do grupo para decidir suas opções eleitorais. Nessas situações, são convocados candidatos políticos e outros interessados, que discursam e ajudam na decisão dos votos do grupo. A grande maioria dos associados participa dessas reuniões. Nem todos se interessam pelas discussões, mas relatam tirar dali o nome dos candidatos em quem vão votar.

Uma coisa que eu acho importante falar é que, aqui, a gente não abre mão do voto consciente. Por isso fazemos muita reunião para discutir política. (...) A cooperativa também tem o grupo de cidadania ativa. Nós participamos da fundação do Fórum de Cooperativismo Popular (coordenador, membro do conselho deliberativo).

No entanto, há alguns cooperados que não se interessam pelas discussões coletivas, rejeitando quaisquer movimentos sociais ou participações políticas. Dizem detestar reuniões, associando-as a perda de tempo e à ineficácia das decisões. Outros, que de nada participam, justificam-se pela pesada carga de trabalho ou por não terem sido direta ou oficialmente convidados pelos colegas. Outros, ainda, dizem que não se interessam porque não entendem, embora a falta de interesse possa ser um dos fatores que dificultem e descontinuem o seu entendimento. Tal constatação é confirmada pelos membros da comissão de formação, que se queixam da pouca participação quando da proposição de palestras, cursos e treinamentos sobre cooperativismo, política, participação social e formas de gestão. Em geral, contudo, o interesse é bem maior do que o constatado em outros trabalhadores da mesma categoria.

Muitos afirmam que começaram a se interessar após o contato com o Sr. Arnóbio e com as reuniões da cooperativa.

Acho que tinham que chamar uma reunião para explicar. Mas acho que o pessoal não vai comparecer, só se fosse junto com a assembléia. Não é culpa deles. Tem muito assunto pra discutir. Na dá tempo de explicar. Acho que com o correr do tempo a gente vai entender melhor (servente).

Percebe-se entre muitos desses trabalhadores a preocupação, o comprometimento e o orgulho pela participação em movimentos políticos e sociais. A quantidade de cooperados engajados é surpreendente.

A gente participa do Ação $\mathcal{E}$ Cidadania, do Shangri-lá, do Casa e Cidadania. (...) Tem também a GT, que é a associação de grupos de produção comunitária do Rio de Janeiro. Eu faço parte da direção (pedreiro).

Tem o Fórum de Economia Solidária (FCP-RJ), sou suplente do delegado estadual no Fórum Brasileiro de economia solidária. Sou também militante do PT (pedreiro).

Participo com alguns colegas de um movimento político chamado Imputecer" [reuniões com políticos e partidários, onde discutem questões políticas e sociais], (meio-oficial). 


\section{Perspectivas futuras, dificuldades e limitações}

Uma das principais frustrações narradas pelos trabalhadores é o fato de dependerem financeiramente de um investidor externo para manter o seu funcionamento. Percebem que só dessa forma conseguem garantir sua subsistência, mas crescem pouco e contribuem para a concentração de renda - discussão muito veiculada entre os grupos de trabalho e de discussões mantidos com as ONGs e com movimentos da Igreja Católica.

Porém, maior que a frustração com a dependência financeira, é a esperança que esses trabalhadores depositam na cooperativa. Os membros mais antigos demonstram preocupações com o preparo dos mais novos para assumirem posições de liderança. Os mais jovens possuem diferentes planos: uns querem ver a cooperativa crescer e continuar trabalhando nela; outros pensam em mudar de função, alcançando algum cargo mais qualificado dentro da cooperativa; outros pensam em preparar-se para assumir um empreendimento próprio (não vinculado à construção civil); há poucos que pensam em encontrar uma vaga em uma outra empresa. Outros ainda relatam gratidão em função de um grande sonho conquistado: o sonho de ter uma casa própria, realizado através dos projetos Shangri-lá ou Casa \& Cidadania.

Entre os que pensam em permanecer na cooperativa, há novamente um desejo de vêla crescer e se desenvolver, de entender melhor sobre política e cooperativismo, de ter um capital próprio para não depender do investimento de terceiros.

O que eu espero é trabalhar mais para fazer subir a cooperativa (...) Se eu puder eu fico sempre aqui, por muitos anos (pedreiro).

Paralelo a tudo o que já foi narrado, há muitas dificuldades e preocupações que ocupam os cooperados, expressas em quase todas as falas. Algumas se referem ao excesso de cobranças e encargos burocráticos para o processo de regularização da cooperativa e à falta de apoio do governo. Outros relatam preocupações com as falsas cooperativas que desacreditam aquelas que colocam em prática os ideais do cooperativismo.

Existe um monte de falsas cooperativas que queimam o filme do movimento, que exploram o trabalhador só para ter mais lucro (meio-oficial).

O governo não apóia. Só apóia aquelas cooperativinhas de artesanato, porque é besteira. Só apóia quando não rende nada (...) Tem que dar crédito. Os impostos não deixam. Não tem quem se responsabilize (coordenador).

Deveria ter apoio do governo para a gente ter mais trabalho - algo para baixar os preços da concorrência, algo que ajudasse a aumentar o salário (coordenador).

Os trabalhadores relatam também inquietações generalizadas com a situação de desigualdade social no país e com a função social do cooperativismo. Preocupam-se em ajudar os colegas em dificuldades e em intervir nos problemas da comunidade. Houve narrativas sobre a sensação de estar na "contramão" da sociedade, em seus ideais de solidariedade e de autogestão, agravada por uma percepção da incompreensão da comunidade e dos próprios familiares.

Tem muita desigualdade social. Isso me desanima. O homem só quer dinheiro e não pensa que, ao contribuir para a desigualdade social, ele está formando o ladrão. Depois ele é assaltado e pensa que não fez nada para sofrer aquilo. Mas ele fez. Ele fez ter a desigualdade que criou o ladrão (servente).

Queremos ajudar. Aí falam que a gente quer ser estrela, que é muita fantasia (servente). 
Às vezes fico desacreditado - não no grupo, mas na sociedade. Tem muito egoísmo. Parece que a gente age na contramão da sociedade. Recebemos muitas críticas dos outros (ajudante).

Às vezes, essa sensação de estar na contramão provoca desânimo, principalmente pela falta de reconhecimento por parte dos colegas, com oscilantes vontades de desistir do empreendimento.

Às vezes dá vontade de largar tudo porque ninguém quer nada. Mas, quando a gente se envolve com o cooperativismo, é um vício. A gente não consegue sair (ajudante).

Há outras dificuldades relativas à viabilidade econômica, como o alto preço dos terrenos, o retraimento do mercado de construção civil, a concorrência no mercado cada vez mais competitivo, a falta de apoio do governo, as limitações impostas pelo desconhecimento e pela falta de "malícia" em questões administrativas, jurídicas, burocráticas e negociais.

O problema é o mercado hoje em dia. Nós não estamos conseguindo achar terreno. Quando consegue, o pessoal bota o preço lá em cima (coordenador).

Nesse quesito, deve ficar claro que não são dificuldades peculiares dessa cooperativa, mas empecilhos pelos quais passam muitos dos pequenos negociantes sem experiência, sem suporte técnico, sem prévia formação acadêmica ou profissional. Entretanto, são obstáculos que esses trabalhadores se esforçam diariamente por vencer; e conseguem, à medida que se mantêm no mercado competitivo e que crescem, conquistando a confiança dos seus clientes e ganhando visibilidade no seu ramo de atuação.

Um grande obstáculo se refere à dificuldade dos cooperados em assumir a liberdade que lhes é atribuída. Autores diversos (Fromm, 1968; Winnicott, 1999; Freud, 1930; Stuart Mill, 1972; Berlin, 1981) advertem-nos sobre a dificuldade humana para assumir as liberdades que lhes são conferidas. Afirmam (os homens) uma luta constante e um anseio interminável pela liberdade; entretanto, quando têm a oportunidade de exercê-la, são poucos os que a assumem. Quando recebem a tão desejada liberdade, percebem que ela não pode vir separada da responsabilidade; que ela não tem nada a ver como mera independência para fazer tudo o que se deseja; que há uma necessidade de freio sobre nossas ações; que é preciso pensar antes de agir; que teremos que assumir as conseqüências trazidas por ela.

Entre outros fatores, há a influência da cultura de submissão com a qual somos acostumados, mas isso não significa que nos falte capacidade para sermos autônomos. A construção da autogestão é um processo lento, que requer enorme esforço e paciência. Há muitas dificuldades em assumir essa liberdade conjugada à responsabilidade. Segundo os cooperados, alguns a tomam de forma isolada e aproveitam-se da falta de controle interno para trabalhar menos ou "morcegar no serviço", como eles mesmos dizem. Também o excesso de tolerância é apontado pelos trabalhadores como algo que propicia abusos, como esses mesmos indicados abaixo.

Tem muita gente que não leva a sério. Tem gente que faz o horário todo, mas enrola no serviço (...) Às vezes até tem problema: alguém que falta muito. Aí é afastado para não empatar o grupo (coordenador).

Há também apontamentos à falta de interesse dos cooperados, deixando grande parte das decisões importantes sob responsabilidade de alguns poucos, sobrecarregando-os e acomodando outros. Em nossa cultura, somos mais ensinados para delegar ou obedecer, e 
menos para assumir responsabilidades ${ }^{5}$. Entretanto, é preciso ter clareza de que a conquista da liberdade inclui a participação e o compromisso.

Tem também a falta de interesse pela reunião. Tem gente que vai forçado, de má vontade. Não sabe o que fazer. Todo mundo tem que ter responsabilidade (pedreiro).

Um outro obstáculo é a tendência ao imediatismo e a dificuldade de previsão. É difícil prever e planejar a longo prazo quando acostumados a muitas faltas e carências. Mesmo com uma grande possibilidade de acerto, prevalecem as soluções imediatistas. Essa falta de preocupação com o planejamento de longo prazo é claramente expressa na fala abaixo, emitida por um dos representantes do conselho deliberativo:

Eu não faço planos não. Na verdade, nunca gostei muito de planos.(...) Quero que a família melhore, ter uma estabilidade. Mas eu não consigo planejar para daqui a um mês, por exemplo. Eu vou vivendo o dia-a-dia. É uma coisa que eu não esquento a cabeça. (...) Eu vou de acordo com a conjuntura do momento (tesoureiro, membro do conselho deliberativo).

Há outras dificuldades que eles mesmos apontam como, por exemplo, a defasagem do grupo em relação à tecnologia e a algumas regras ou leis referentes ao ambiente de trabalho. Quanto à tecnologia, apontam a falta de conhecimento técnico, de poder aquisitivo e de apoio coletivo para investir na modernização do grupo. Também há alguns que negam qualquer tentativa de modernização ou de introdução de máquinas no trabalho, considerando que isso contribuiria para a redução de postos de trabalho.

Recebemos muitas críticas dos outros. Minha irmã mesmo: ela faz faculdade e diz que a gente é burro e limitado, que não sabe usar tecnologia e que não quer aprender (ajudante).

Dizem que a gente, peão, é tudo ignorante, mas eu não sou. Tecnologia não é para qualquer um. Não tem acesso (ajudante).

Se a gente compra máquina, a gente tira o trabalho do colega. Não pode um pai de família ficar sem trabalho (servente).

Como forma de suprir essa defasagem e, na tentativa de atender um dos princípios inspirados pelo cooperativismo internacional (princípio de educação, treinamento e informação), pelo menos uma vez por mês ocorrem reuniões de formação: momentos de troca de idéias sobre cooperativismo, solidariedade, trabalho e de aprendizagem sobre os ofícios. Discutem-se também questões políticas e sociais. É um momento de integração e de contato dos membros da cooperativa com entidades de suporte, como algumas ONGs e instituições religiosas e sociais.

O investimento em formação e a possibilidade de crescimento profissional dentro da cooperativa estão na contracorrente da realidade da construção civil em nosso país. Nesse campo de trabalho, em geral, não há ascensão profissional. A maioria dos trabalhadores da construção civil, quando não se tornam eternos profissionais autônomos, passam o resto de suas vidas assumindo a mesma função ao longo dos anos, com poucas possibilidades de mudanças. Nesse sentido, como já dissemos, a organização dessa cooperativa aproxima-se da organização das corporações de ofícios, nas quais as funções eram pacientemente ensinadas e passava-se de aprendiz para meio-oficial, de meio-oficial para artesão e assim sucessivamente.

Também há restrições em relação ao ambiente de trabalho - questões concernentes a todo o campo da construção civil. São, em geral, ambientes sujos, com muita poeira e alto nível de ruído, além de serem propícios a ocorrência de acidentes diversos. A cooperativa não

5 Segundo Vianna (1996), na história do Brasil, construiu-se uma noção de democracia e de direito como concessão, cuja regra passa a se dar a partir de favores e de apadrinhamentos. O brasileiro não se reconhece em seu papel ativo: reclama com o vizinho, mas não cobra; aceita a promessa do político, mas a esquece; espera sempre que se faça e que se decida por ele. 
possui um técnico ou um engenheiro de segurança do trabalho, embora exista uma comissão responsável por possibilitar a redução e a prevenção de acidentes nas obras. Essa comissão atua através de orientações e de recomendações nas reuniões e no dia-a-dia, no ambiente de trabalho.

Semanalmente, os cooperados contribuem para um fundo de reserva, destinado à cobertura das despesas em caso de acidentes e adoecimentos. Em caso de necessidade de medicamentos não fornecidos pelo SUS (Sistema Único de Saúde), o fundo de solidariedade compra o remédio, não sendo necessária a devolução de seu valor à cooperativa. Outros destinos dados a esse fundo são: compra de material para as reuniões de formação, auxílio a movimentos populares e suporte a atividades de integração do grupo entre si e de suas famílias.

Entre os trabalhadores que estão há mais tempo na cooperativa, há grande preocupação quanto à aposentadoria. Muitos já possuem idade e tempo de serviço suficiente para se aposentarem, mas adiam essa decisão por dois motivos: temem pelo futuro da cooperativa sem sua participação; preocupam-se com o baixo valor que receberiam pelo INSS, que é de apenas um salário mínimo, enquanto na cooperativa retiram pelo menos o triplo desse valor.

Também há preocupações com o fato de não terem proteção social. Sabem que o trabalho que exercem impõe-lhes riscos diários e gostariam de ter um seguro ou um plano de saúde, pois não confiam na assistência pública. Isso é para eles um grande problema, pois não há seguradoras ou agências de saúde que aceitem fazer planos para trabalhadores dessa área de atuação. Essa preocupação é demonstrada pela fala abaixo:

A cooperativa podia ter um plano de saúde, cesta básica. Eles estão até tentando ver convênios, mas ninguém quer dar plano de saúde para a construção civil. A gente tem que fazer um seguro de vida, mas a mensalidade é muito alta e o valor recebido é só oito mil reais. Ninguém quer fazer seguro ou plano de saúde para a construção civil (coordenador de obra).

\section{Conclusão e considerações finais}

Durante o período de entrevistas, muitas pessoas foram ouvidas - a maior parte dos cooperados -, embora tenhamos tido que entrevistar mais detidamente as lideranças e os membros mais antigos do grupo para que pudéssemos reconstituir sua história. Nesse percurso, observamos entre os trabalhadores percepções muito distintas, que vão do empenho constante em fortalecer o espírito da cooperativa à visão daquele espaço como uma mera oportunidade de trabalho. Tais diferenças revelam, além do maior ou menor grau de envolvimento na construção do processo autogestionário, decorrente das histórias individuais de vida e da passagem por vários coletivos, a persistência de uma cultura própria da condição de assalariado, difícil de ser superada.

Enfim, limitações existem, e formas de superá-las estão sendo cotidianamente tentadas por esses trabalhadores. Até o presente momento, apesar de todas as dificuldades de compreensão sobre o cooperativismo e para assumir efetivamente esse papel de autonomia, o que está claro para eles é a existência de um espaço de liberdade onde podem opinar e divergir. Está claro para eles o esforço do grupo em incentivar essa participação e a dimensão social que tem ganhado suas iniciativas. Referimo-nos à enorme força que têm demonstrado ter os empreendimentos solidários no sentido de possibilitar a segmentos desprivilegiados a chance de vislumbrar uma oportunidade no mercado de trabalho. Esses trabalhadores sentem 
orgulho de fazer parte desse grupo de cooperados, principalmente pelo alto reconhecimento que dizem haver em relação à qualidade do seu trabalho.

Muitos gostariam de ser mais eficientes ao "vestir a camisa da cooperativa" e encontram grandes empecilhos, como a falta ou carência de suporte técnico, a dificuldade de traduzir idéias em ações e a pouca compreensão dos discursos que ouvem quando orientados por outros profissionais ou entidades. Entretanto, defendem a cooperativa como o seu espaço de trabalho e reconhecem sua propriedade como coletiva, incluindo a si próprios nessa coletividade. Sabem que, mesmo quando calados, votam e suas opiniões têm peso sobre o grupo. Sabem também que quando votam em prol da maioria fortalecem posições dominantes. Mas, nesses casos, só contam com a confiança naqueles em cujos votos se apoiaram.

Mais uma vez, apontamos para um longo caminho de construção do processo autogestionário - um caminho tortuoso que tropeça em inúmeros obstáculos. Apesar disso, a força de vontade desses grupos e a constatação da necessidade de sobrevivência não os deixa desistir. Sofrem altos e baixos, mas continuam firmes e fortes. No percurso, vão aprendendo a cada momento que trabalhar dá trabalho, mas apostam nos benefícios desse esforço, alguns dos quais já puderam ser vislumbrados em nas descrições acima.

Apontamos algumas características que são peculiares à cooperativa Constrói Fácil: forte busca por autonomia e incentivo à participação, incentivo ao conhecimento e à capacitação, estabilidade que reduz a insegurança no trabalho, retiradas acima da média salarial da categoria, possibilidade de ascensão, igualdade de direitos, auxílio coletivo em caso de adoecimento ou acidentes, uso de equipamentos - não por obrigatoriedade, mas a partir de um reconhecimento de sua necessidade -, incentivo à participação e influência nas decisões da cooperativa. Não podemos deixar de colocar aqui também a melhoria das condições de vida desses trabalhadores, propiciada por um maior ganho financeiro e pela própria casa que puderam ou poderão construir graças ao incentivo e à cooperação dos colegas de trabalho. Trata-se de uma quebra da precariedade em um campo de imensa e histórica precariedade social.

Quanto à busca do ideal de emancipação social, consideramos que a economia solidária é o próprio resultado do começo de uma experiência de emancipação. Ao tomarem iniciativas, ao se autoperceberem como capazes de assumirem o rumo de suas próprias vidas; e mais: quando se propõem a interferir em outras vidas, no sentido de melhorá-las, através de ações de solidariedade diversas, estão nada mais do que buscando emancipar-se, assumindo sua liberdade e libertando outros.

$\mathrm{Na}$ qualidade de alternativa a situações de exclusão social, os empreendimentos cooperativos não se apresentam apenas como uma alternativa econômica, mas como parte de um movimento social. É um processo que acontece à medida que a população supera as saídas individuais e recorre a alternativas coletivas. O movimento nasce a partir de um problema local e imediato, mas seu desenvolvimento tende a aumentar as reivindicações para as esferas mais amplas da realidade social. A sua grande importância está no exercício de organização e enfrentamento que se dá a partir das dificuldades percebidas. Seu campo de atuação amplia-se à medida que outros problemas vão sendo percebidos e que se reconhecem na necessidade de atuar coletivamente em sua resolução. E assim o fazem, aos poucos e cotidianamente.

Atualmente, destaca-se a articulação e as mobilizações realizadas pelos fóruns de cooperativismo popular nos níveis locais, regionais e nacional, promovendo e estendendo discussões e levando questões locais a âmbitos maiores, contribuindo para o fortalecimento e para a maior abrangência do movimento. 
Os principais resultados da iniciativa dizem respeito ao aumento da mobilização coletiva, ao envolvimento progressivo em atividades junto à comunidade, que resulta no estabelecimento de uma maior autonomia de seus membros, no que se refere à participação e organização em ações locais. Os cooperados participam ativamente de atividades políticas, sociais, cooperativas e comunitárias, superando o imobilismo e avançando na consolidação de uma organização social mais fortalecida. Registram-se momentos altos como a implementação do projeto Casa \& Cidadania, a organização de reuniões específicas de formação, a relevância dada às assembléias deliberativas, a filiação a partidos políticos e a destinação de recursos para fins sociais e comunitários e fundos de reserva para cuidados à saúde dos cooperados. Vale citar o questionamento dos valores capitalistas e a instituição de atitudes e movimentos que contestam a submissão ao trabalho, o desemprego e as desigualdades sociais.

Como iniciativa governamental, a recente criação da Senaes (Secretaria Nacional de Economia Solidária) contribui para o avanço, aumentando a visibilidade do movimento e fortalecendo as mesas de discussões. Prova dessa maior visibilidade é a inclusão desse do tema da economia solidária na agenda de discussões de movimentos como o Fórum Social, a Associação Brasileira de Psicologia Social, a Cáritas do Brasil, algumas universidades públicas e privadas, diversas outras instituições não governamentais, além da presença do tema no planejamento social de diversos municípios e estados brasileiros.

No que tange à saúde, já se percebem na Constrói Fácil intervenções no sentido de propiciar melhores condições de segurança e saúde, através da compra de equipamentos, da realização de reuniões de formação para melhor informar e qualificar os trabalhadores, além da adoção de uma perspectiva do trabalho não focada no lucro, mas na melhoria da qualidade de vida dos indivíduos.

Destacamos algumas importantes perspectivas do movimento cooperativista: a continuidade das ações de mobilização local e comunitária e o fortalecimento e a organização dessa e de outras iniciativas ligadas a processos de autonomia individual e coletiva; ações destinadas à geração local de renda, buscando o envolvimento das comunidades, o aumento da visibilidade de suas ações e, de forma abrangente e em longo prazo, a redução do desemprego, da precarização do trabalho e das desigualdades sociais.

Cabe destacar também a necessidade de uma maior inclusão das discussões sobre saúde e sobre a utilização de tecnologias produtivas nas pautas de trabalho dos fóruns regionais e nacional de economia solidária. Existem algumas iniciativas isoladas, mas não são assuntos contemplados, por exemplo, pelos princípios da economia solidária. Sabemos, no que se refere às tecnologias produtivas, que há dificuldades relacionadas à escassez de recursos financeiros, pois demandam um alto investimento. Porém, é uma discussão importante a ser incluída na pauta de reivindicações dos movimentos cooperativistas solidários do país.

Em relação à promoção da saúde, é pertinente à discussão o fato dos cooperados estudados se preocuparem com a constituição de uma comissão de segurança e com a divulgação de normas e de procedimentos de proteção em suas reuniões. É interessante o quanto os membros dessa comissão se preocupam em organizar o ambiente de trabalho e em transmitir informações sobre saúde e segurança a todos os colegas. Há questionamentos quanto aos seus direitos enquanto trabalhadores, demonstrados através das críticas ao Sistema Único de Saúde e das preocupações quanto a ter um seguro de vida freqüentemente negado pelas seguradoras - ou um plano de saúde, além de receios em relação à sua aposentadoria.

O zelo e a dedicação pela cooperativa são repetidamente demonstrados em suas atitudes de incentivo aos colegas, de defesa aos princípios do cooperativismo e na abdicação revelada por alguns cooperados que, segundo suas falas, já poderiam ter se aposentado, mas 
adiam a decisão por se sentirem responsáveis pela cooperativa, por receio de atrapalhar o seu progresso e pela necessidade que sentem de preparar sucessores com os mesmos ideais em relação à doutrina do cooperativismo e com o mesmo comprometimento que afirmam ter.

Cabe enfatizar que a expectativa desta pesquisa não foi a de descrever, por si só, e no curto prazo, mudanças de porte e impactos mensuráveis em resultados quantificáveis e de grande significação, mas registrar os avanços da experiência investigada por esse processo, colocando-se a seu serviço para tornar inteligíveis os seus movimentos no sentido do desenvolvimento. Sabe-se que as mudanças macro dependem de um contexto social profundamente mais amplo e complexo. Como afirma Pivetta (2002), "não existirá... uma ilha da fantasia sem a sinergia de um projeto de Estado e Nação que garanta a sustentabilidade social, ambiental e econômica do todo". No entanto, como Koga (2003), citando Ladislau Dowbor, afirma que uma das mais significativas riquezas do desenvolvimento local reside no fato de poder-se adequar as ações às condições diferenciadas que as populações enfrentam. Isso não implica, naturalmente, que as políticas sociais possam se resumir à ação local, mas seriam fundamentais para se estabelecerem, de fato, políticas universais que garantam ao mesmo tempo igualdade e eqüidade.

Da forma como têm se constituído, muitas dessas alternativas podem colocar-se como um exemplo, como um caminho a ser seguido por outras tentativas, como movimento a ser valorizado e apoiado por entidades diversas (pesquisadores, instituições, poder público, ONGs). É também o princípio e a contribuição essencial para a construção de uma sociedade mais justa, mais humana e mais igualitária. Não podemos mudar o todo, mas podemos ir mudando aos poucos.

Cada vez mais, a forma como tem se constituído nossa sociedade mostra-nos o quanto é difícil agir sozinho e o quanto a experiência da coletividade pode tornar possível alternativas que seriam impensáveis no âmbito individual. E é na realização dessas tarefas que a coletividade faz mais falta. Mas é também a partir delas que tal coletividade pode se realizar. Se vier a existir uma comunidade solidária no mundo dos indivíduos, só poderá ser (e precisa sê-lo) uma comunidade tecida em conjunto a partir do compartilhamento e do cuidado mútuo; haverá de ser uma comunidade de interesse e responsabilidade em relação aos direitos iguais de sermos humanos e à igual capacidade de agirmos em defesa de direitos fundamentais e de melhorias da qualidade de vida.

\section{Referências}

Albuquerque, P. P. (2003). Autogestão. In A. D. Cattani (Org.). A outra economia (pp. 20-26). Porto Alegre: Veraz Editores.

Barros, M. E. B. B. (Org.). (1999). Psicologia: questões contemporâneas. Vitória: EDUFES.

Berlin, I. (1981). Dois conceitos de liberdade. In Quatro ensaios sobre a liberdade. Brasília: UNB.

França Filho, G. C. (2002). Terceiro setor, Economia Social, Economia Solidária e Economia Popular: traçando fronteiras conceituais. Bahia Análise EB Dados, 12 (1), 9-19.

Freud, S. (1995) O mal estar da civilização. In Edição Standard das Obras completas de Sigmund Freud. Rio de Janeiro: Imago.

Fromm, E. (1968) O medo à liberdade. Rio de Janeiro: Zahar.

Koga, D. (2003). Cidades entre territórios de vida e territórios vividos. Serviços Social e Sociedade, 72. 
Lisboa, A. de M. (1999). A emergência das redes de economia popular no Brasil. In N. M. Dal Ri (Org.) Economia solidária: o desafio da democratização das relações de trabalho. São Paulo: Arte Ciência.

Mendes, R. \& Dias, E. C. (1991). Da medicina do trabalho à saúde do trabalhador. Revista de Saúde Pública, 25 (5), 341-349.

Mills, C. W. (1972). Da razão à liberdade. In A imaginação simbólica. Rio de Janeiro: Zahar.

Pivetta, F. (2002). Laboratório territorial como instância para a promoção da saúde - contribuição para as discussões acerca do programa DLIS Manguinhos. In L. Zancan, R. Bodstein \& W. B. Marcondes (Orgs.) Promoção da Saúde como caminho para o Desenvolvimento Local (pp. 247-271). Rio de Janeiro: Abrasco.

Vianna, L. W. (1996). Caminhos e descaminhos da revolução passiva à brasileira. Dados, 39 (3).

Winnicott, D. W. (1999). A liberdade. In Tudo começa em casa (pp. 237-248). São Paulo: Martins Fontes.

Endereços para correspondência:

ebusnardo@hotmail.com,nani.ab@gmail.com

Recebido em: 05/05/2005

Pareceres enviados em: 23/06/2005

Aprovado em: 09/07/2005 